\title{
The influence of sweeteners in probiotic Petit Suisse cheese in concentrations equivalent to that of sucrose
}

\author{
E. A. Esmerino, ${ }^{* 1}$ A. G. Cruz, ${ }^{*} \dagger$ E. P. R. Pereira, ${ }^{*}$ J. B. Rodrigues, ${ }^{*}$ J. A. F. Faria, ${ }^{*}$ and H. M. A. Bolini ${ }^{*}$ \\ *Universidade Estadual de Campinas (UNICAMP), Faculdade de Engenharia de Alimentos (FEA), Cidade Universitária Zeferino Vaz, \\ 13083-862 Campinas, São Paulo, Brazil \\ †Instituto Federal de Educação, Ciência e Tecnologia do Rio de Janeiro (IFRJ), Mestrado Profissional em Ciência e Tecnologia de Alimentos \\ (PGCTA), Maracanã, 20270-021 Rio de Janeiro, Brazil
}

\begin{abstract}
As in the case of probiotic functional foods in recent years, demand has increased notably for light or diet foods with added sweeteners. However, little is known about the effect of different sweeteners on the microorganisms present. Thus, the objective of the current study was to establish the ideal sucrose concentration and equivalent concentrations of different sweeteners and to determine, by microbiological analyses, the influence of these compounds on the viability of the starter and probiotic cultures used in the production of strawberry-flavored Petit Suisse cheese during its shelf life. The ideal sucrose concentration was determined using the just-about-right (JAR) scale, and the equivalent concentrations of the sweeteners were subsequently determined by the magnitude estimation method. Microbiological analyses were also carried out to check the viability of the cultures during the product's shelf life. The results showed that the compounds Neotame (NutraSweet, Chicago, IL) and stevia presented, respectively, the greatest and least sweetening power of the sweeteners tested. None of the sweeteners used in this study exerted a negative effect on the viability of the starter or probiotic cultures, and thus we were able to obtain a probiotic, functional food with reduced calorie content.
\end{abstract}

Key words: Petit Suisse cheese, probiotic, sweetener, magnitude estimation

\section{INTRODUCTION}

Demand for functional foods has increased notably in recent years (Granato et al., 2010). When probiotics or prebiotics are added to these foods as biologically active components, they produce metabolic and physiological health benefits in addition to their basic nutritional properties (Siró et al., 2008). Petit Suisse cheese has a

Received January 24, 2013.

Accepted April 24, 2013.

${ }^{1}$ Corresponding author: ealmeida@fea.unicamp.br high moisture content and a creamy consistency. It is produced from a mass obtained using a mixed coagulation process, and can be added to sweet and savory condiments to be consumed fresh (Brasil Ministério da Agricultura, Pecuária e Abastecimento, 1996). Because of its characteristics, it is an appropriate vehicle for probiotic bacteria because it requires no maturation period and has a relatively short shelf life (Helle et al., 2003).

In parallel, low- or reduced-caloric food products with sweeteners added (as sucrose substitutes) are becoming increasingly prominent in the marketplace. According to the Brazilian Association of Industries for Diet and Special Needs Foods (ABIAD), the light or diet food product market grew about $800 \%$ in the last $10 \mathrm{yr}$ (ABIAD, 2011). When planning to substitute sucrose with a sweetening substance, it is important to know the sweetener well and to determine the concentration that best portrays an equivalent product sweetened with sucrose, in terms of intensity and sensory profile (Souza et al., 2011). First, the ideal concentration of sucrose for the specific product should be determined and then the equivalent sweetness of each sweetener measured. Of the existing sensory techniques, the just-about-right (JAR) scale is one of the effective methods most used (Gagula et al., 2007) because of both the reliability and validity of its results and its simplicity in use by the sensory panel (Meilgaard et al., 2006). Various methodologies can be used to obtain information about the equivalence in sweetness of a sweetener. However, the magnitude estimation method stands out, with normalized graphical representation of the results using Steven's Law and the Power Function (Stone and Oliver, 1969), which, by staggering the ratio, makes it possible to get a direct measurement of the sweetness intensity.

The introduction of sweeteners can result in significant sensory alterations in a product, particularly in appearance, texture, and flavor (Lawless and Heymann, 2010). However, little is known about the influence of these compounds on the viability of the probiotic bacteria used in functional foods, such as probiotic lactic products. Thus, the objectives of the present study 
were to establish the ideal sucrose concentration and equivalent concentrations of the sweeteners stevia, sucralose, aspartame, and Neotame (NutraSweet Corp., Chicago, IL), and to verify, by microbiological analyses, the viability of the starter and probiotic cultures used in strawberry-flavored Petit Suisse cheeses during the product's shelf life.

\section{MATERIALS AND METHODS}

\section{Ingredients}

The Petit Suisse probiotic cheese was manufactured using the following ingredients: pasteurized milk type A (Ati Latte, Atatiba, São Paulo, Brazil), calcium chloride (0.25 g/L, ECIBRA, Santo Amaro, São Paulo, Brazil), starter culture (3\% wt/vol, Streptococcus thermophilus TA 040, Danisco, São Paulo, São Paulo, Brazil), probiotic cultures $(5 \% \mathrm{wt} / \mathrm{vol}$ Lactobacillus acidophilus LA 14, Bifidobacterium lactis BL 04, Danisco), rennet (Chr. Hansen, Valinhos, São Paulo, Brazil), sterilized milk cream (25\% wt/wt fat, Nestlé, Araçatuba, São Paulo, Brazil), strawberry pulp (Icefruit, Tatuí, São Paulo, Brazil), artificial strawberry colorant (Arcolor, ArcoÍris Brasil Ltda, São Paulo, São Paulo, Brazil), strawberry aroma (Duas Rodas Industrial Ltda, Campinas, São Paulo, Brazil), xanthan gum (Keltrol, CPKelco, Limeira, São Paulo, Brazil), carrageenan gum (LRA 50, CPKelco, Limeira), and guar gum (Tec Pharma, São Paulo, São Paulo, Brazil).

\section{Sweeteners}

Four sweeteners were used in Petit Suisse probiotic cheese production, all of which are allowed by the current Brazilian Legislation (Brasil Agência Nacional de Vigilância Sanitária, 2008), beyond that of sucrose: aspartame (NutraSweet, Chicago, IL), Neotame (NutraSweet), sucralose (NutraMax, Catanduva, São Paulo, Brazil), stevia (Estévia com 90\% de rebaudioside, Clariant, São Paulo, São Paulo, Brazil), and refined sugar (Açúcar Refinado, União, Sertãozinho, São Paulo, Brazil).

\section{Probiotic Petit Suisse Cheese Processing}

The base mass (quark cheese) and Petit Suisse cheese were prepared according to the methodology described by Cardarelli et al. (2008) with some changes, including the probiotic culture used, using cultures of $L$. acidophilus and B. lactis. The base mass (quark cheese) was obtained by heating pasteurized milk to 37 to $38^{\circ} \mathrm{C}$, transferring it to isothermal containers and then adding the starter and probiotic cultures by direct inoculation (direct vat starter), followed by homogenization. The containers with the inoculated milk were maintained at $37^{\circ} \mathrm{C}$ until $\mathrm{pH}$ reached 6.3 to 6.5 , and then the rennet was added, and the mixture rehomogenized and maintained at $37^{\circ} \mathrm{C}$ until a curd was formed with $\mathrm{pH}$ of about 5.6 to 5.8. The curd was then carefully cut into cubes, which were placed in sterile cloth sacks to drain off the whey at a temperature of $10^{\circ} \mathrm{C}$ for $15 \mathrm{~h}$. After drainage, the quark cheese was placed in sterile containers and stored at $4^{\circ} \mathrm{C}$ until mixed with the other ingredients to make the Petit Suisse cheese. All the remaining ingredients were then added and homogenized in a multi-processor for 30 min (Estephan rpm 1750/3500, Geiger, Pinhais, Paraná, Brazil), until a consistent mass was obtained. After homogenization, appropriate containers were filled with cheese and maintained under refrigeration at $4^{\circ} \mathrm{C}$ for $28 \mathrm{~d}$. The ideal test and magnitude estimation test were applied the day after filling. The processing was performed twice, on 2 different days.

\section{Determination of the Ideal Sucrose Concentration}

Five formulations of probiotic Petit Suisse cheese were prepared, varying only in sucrose concentration: $7.5,11,14.5,18$, and $21.5 \%$ (wt/wt). The central point was defined according to estimates of the amounts of sucrose normally used in commercial dairy products and considering a previous study with Petit Suisse cheese (Souza et al., 2011). Fifty-two panelists were used, all Petit Suisse consumers, recruited among students and employees on the university campus, aged between 18 and $45 \mathrm{yr}$, and the majority (70\%) being women. The panelists evaluated the samples using a 9-cm nonstructured scale anchored at the extreme left by "extremely less sweet than the ideal" and at the extreme right by "extremely sweeter than the ideal," the central point being the ideal concentration to add to the product (Meilgaard et al., 2004). The panelists were requested to indicate on the scale the intensity of the perceived sweet stimulus.

The probiotic Petit Suisse cheese was presented monadically to the panelists according to a complete block design (MacFie et al., 1989), $5 \mathrm{~d}$ after the processing. Samples were presented in disposable $50-\mathrm{mL}$ white plastic cups, coded with 3-digit numerals chosen at random, so as not to influence the panelists. Water and water biscuits were also provided to rinse out the mouth and neutralize the flavors between samples. The samples were served in individual booths in the Sensory Analysis Laboratory of the Department of Food and Nutrition (DEPAN) of the State University of Campinas (UNICAMP), Brazil. The booths were equipped with the FIZZ Network Sensory Software (Biosystemes, Couternon, France). 


\section{Preselection of Panelists}

To efficiently analyze the data of some sensory tests, the taste panel must have adequate discriminatory power. Thus, a preselection was carried out of the candidate panelists for the magnitude estimation test of the different sweeteners used in the strawberry-flavored probiotic Petit Suisse cheeses. A total of 20 candidates were recruited, all consumers of the product having no restrictions in consuming the product and showing interest in taking part in the test.

In the tests, the candidates were instructed to evaluate the samples from left to right, and identify, according to the coding, which sample was different from the others. The discriminative power of was evaluated by Wald's sequential analysis (Amerina et al., 1965), using triangular difference tests with a significant difference at the $1 \%$ level with respect to sweetness, the objective being to select the candidates best able to discriminate the samples. Each candidate performed 3 triangular tests per day to preserve their sensory capacity. The parameters used to analyze the discriminatory capacity were prefixed at $\rho 0=0.45$ (maximum acceptable lack of ability), $\rho 1=0.70$ (minimum acceptable ability), and for the risks $\alpha=0.05$ (probability of accepting a candidate without acuity) and $\beta=0.05$ (probability of rejecting a candidate without acuity) (Moraes and Bolini, 2010). Having defined the parameters, 2 lines of equation were obtained and used to construct the Wald analysis figure. For these parameters, a graph with 3 defined areas was obtained: acceptance area, indecisive area, and rejection area of the panelists. Thus, the panelists were selected or rejected according to the number of correct replies in the triangular tests applied. In the end, 15 panelists were selected for the determination of sweetness equivalence of the Petit Suisse cheeses sweetened with different sweeteners.

\section{Sweetness Equivalence}

Fifteen panelists, selected using Wald sequential analysis and trained in the use of the magnitude scale for samples with different sweetness intensities, were used to determine sweetness equivalence. Training consisted of an explanation of the methodology used, the correct use of the magnitude scale and an explanation of the existence of samples with intensities different to that of the reference sample. After training, the panelists were directed to the booths of the sensory analysis laboratory of DEPAN/UNICAMP, where they carried out affective analyses of samples sweetened with the different sweeteners and sucrose, on different days. A series of concentrations was used to evaluate each sweetener in the strawberry-flavored probiotic Petit Suisse cheeses. Table 1 shows the concentrations used in the magnitude estimation test. The central concentrations used in the determination of sweetness equivalence were based on data from the literature (Cardoso and Bolini, 2007; Palazzo et al., 2011), and the other concentrations were calculated using a multiplication factor of 1.6 (Cardoso et al., 2004). Five concentrations were determined for each sweetener used, and having defined these concentrations, the amounts were weighed, added to the probiotic Petit Suisse cheeses, and homogenized.

The samples were served to the panelists at $4 \pm$ $2^{\circ} \mathrm{C}$ in individual booths, placed in disposable $50-\mathrm{mL}$ plastic cups, coded at random with 3 digits, using balanced complete blocks (MacFie et al., 1989). They were accompanied by a reference strawberry-flavored probiotic Petit Suisse cheese, coded with the letter R, which was sweetened with the ideal concentration of sucrose as found using the JAR scale. The selected and trained panelists received the reference sample with its intensity designated by an arbitrary sweetness score of 100, followed by various coded samples at random, with higher and lower intensities compared with the reference, as already experienced during training. The panelists were requested to designate sweetness intensities to the coded samples in relation to the reference sample. For example, if a sample presented half the sweetness intensity of the reference sample, it should receive a score of 50, if it presented twice the sweetness, it should receive a score of 200 , and so on, not being permitted to award scores of 0 to the samples.

\section{Microbiological Analyses}

Because no preservatives were included in the Petit Suisse cheeses produced here, which could affect the

Table 1. Concentrations of sucrose, sucralose, stevia, Neotame, and aspartame to determine sweetness equivalence, using the magnitude scale, of a concentration of $15.2 \%$ sucrose in probiotic Petit Suisse cheese

\begin{tabular}{|c|c|c|c|c|c|}
\hline \multirow{2}{*}{$\frac{\text { Sweetener }}{\text { Sucrose }}$} & \multicolumn{5}{|c|}{ Concentration ( $\%$ wt $/ w t)$} \\
\hline & 5.94 & 9.50 & 15.20 & 24.32 & 38.91 \\
\hline Sucralose & 0.0095 & 0.0152 & 0.0243 & 0.0389 & 0.0622 \\
\hline Stevia & 0.0594 & 0.0950 & 0.1520 & 0.2432 & 0.3891 \\
\hline Aspartame & 0.0415 & 0.0523 & 0.0836 & 0.1338 & 0.2140 \\
\hline Neotame $^{1}$ & 0.0244 & 0.0016 & 0.0025 & 0.0040 & 0.0064 \\
\hline
\end{tabular}

${ }^{1}$ NutraSweet Corp. (Chicago, IL). 
probiotic cultures, shelf life was only $28 \mathrm{~d}$, shorter than that of the conventional commercial product (Pereira et al., 2010). Thus, the viabilities of the cultures of Streptococcus thermophilus, Lactobacillus acidophilus, and Bifidobacterium lactis were monitored throughout the shelf life of the Petit Suisse cheeses, in triplicate, at 1, 14, and 28 d. The Streptococcus thermophilus count was determined by pour plating $1 \mathrm{~mL}$ of each dilution in M17 agar (Oxoid, Basingstoke, UK) and incubating aerobically at $37^{\circ} \mathrm{C}$ for $2 \mathrm{~d}$ (Pereira et al., 2010). The Lactobacillus acidophilus count was determined by pour plating $1 \mathrm{~mL}$ of each dilution in de Man, Rogosa, Sharpe (MRS) agar with the addition of $0.15 \%$ (wt/ vol) bile salts and anaerobic incubation (Anaerogen anaerobic system, Oxoid) at $37^{\circ} \mathrm{C}$ for $3 \mathrm{~d}$ (Cruz et al., 2012a,b, 2013; Karimi et al., 2012). Bifidobacterium lactis was counted by pour plating $1 \mathrm{~mL}$ of each dilution in MRS agar (Oxoid) with the addition of sodium propionate $(0.3 \mathrm{~g} / 100 \mathrm{~mL})$ and lithium chloride $(0.2$ $\mathrm{g} / 100 \mathrm{~mL}$ ) and incubating anaerobically (Anaerogen anaerobic system, Oxoid) at $37^{\circ} \mathrm{C}$ for $3 \mathrm{~d}$ (Cruz et al., 2010; Castro et al., 2013a,b). All microbiological analyses were carried out in triplicate, and the viable cells were counted after the determined incubation period and expressed as the log colony-forming units per gram $(\log \mathrm{cfu} / \mathrm{g})$.

\section{Statistical Analysis}

The results of the sensory analysis of the probiotic Petit Suisse cheese samples using the JAR scale were obtained by way of the FIZZ Network Sensory Software (Biosystemes), and analyzed by a simple linear regression analysis and using the bar histogram analysis as suggested by Vickers (1998), using Excel 2007 for Windows (Microsoft Corp., Redmond, WA). For the magnitude estimation method, the estimated sweetness magnitude values were converted into logarithmic values and expressed as the geometric mean. The curves for concentration versus sensory response for each sweetener corresponded to a power function with the following characteristics: $\mathrm{S}=a \cdot \mathrm{C}^{n}$, where $\mathrm{S}$ is the perceived sensation, $\mathrm{C}$ is the concentration of the stimulus, $a$ is the antilog of the value for $\mathrm{y}$ on the intercept, and $n$ is the angular coefficient of the straight line obtained (Moskowitz, 1974; Stone et al., 2012).

\section{RESULTS AND DISCUSSION}

\section{Determination of the Ideal Sucrose Concentration}

After obtaining the data from the FIZZ Network Sensory Software (Biosystemes), the means of the scores awarded by the panelists for each sucrose concentra- tion added to the product were calculated. A straight line was obtained from the calculation of the means, intercept, and slope, as shown in Figure 1. From the equation of the straight line, the sucrose concentration necessary to obtain the sweetness considered ideal for the strawberry-flavored Petit Suisse cheese could be determined, and was established as $15.17 \%$, which was rounded to $15.2 \%$ to facilitate subsequent experiments.

The JAR scale has been shown to be effective in the optimization of numerous foods, including lemonades (Epler and Kemp, 1998), apples (Hampson et al., 2000), rice (Suwansri et al., 2002), tortilla chips (Meullenet et al., 2002), milk puddings (Ares et al., 2009), and a symbiotic soymilk beverage (Mondragón-Bernal et al., 2010). Other studies have aimed to specifically elucidate the ideal sucrose concentration to add to products such as mate tea (Cardoso et al., 2004), pineapple juice (Marcellini et al., 2005), peach nectar (Cardoso and Bolini, 2007), and mango nectar (Cadena and Bolini, 2012). In a study with conventional Petit Suisse cheese (Souza et al., 2011), a concentration of $17 \%$ (wt/vol) sucrose was determined as ideal for the product, slightly higher than the value found in the present study, which could be explained by the use of different ingredients and distinct cultures. It was possible to show that the ideal sucrose concentration varied according to the type of product. Such variations are expected and likely exist because of interactions between components in the product.

Figure 2 gives a general view of the distribution of scores among the different sucrose concentrations. Considering a 9-point scale, where -4.5 corresponded to extremely less sweet than the ideal, +4.5 to extremely sweeter than the ideal, and the central point to the ideal sweetness, it can be seen that the samples with $14.5 \%$ and $18 \%$ sucrose presented a sweet taste closest to that considered ideal. The magnitude estimation method was used to provide the ideal sweetness in the probiotic Petit Suisse cheese and, in addition to the concentrations to be added to provide a sweetness equivalent to $15.2 \%$ sucrose, it was used to determine the sweetening power of the sweeteners used.

\section{Determination of Sweetness Equivalence}

For the data analysis, the geometric mean of the values awarded by each of the 15 panelists was calculated. The results for each panelist were then normalized, dividing the value given by each panelist by his or her respective geometric mean. Using the normalized data, the results of all the panelists were used to calculate the geometric mean of each sucrose concentration and of the different sweeteners. After obtaining these means, the logarithm of each concentration and the geometric 


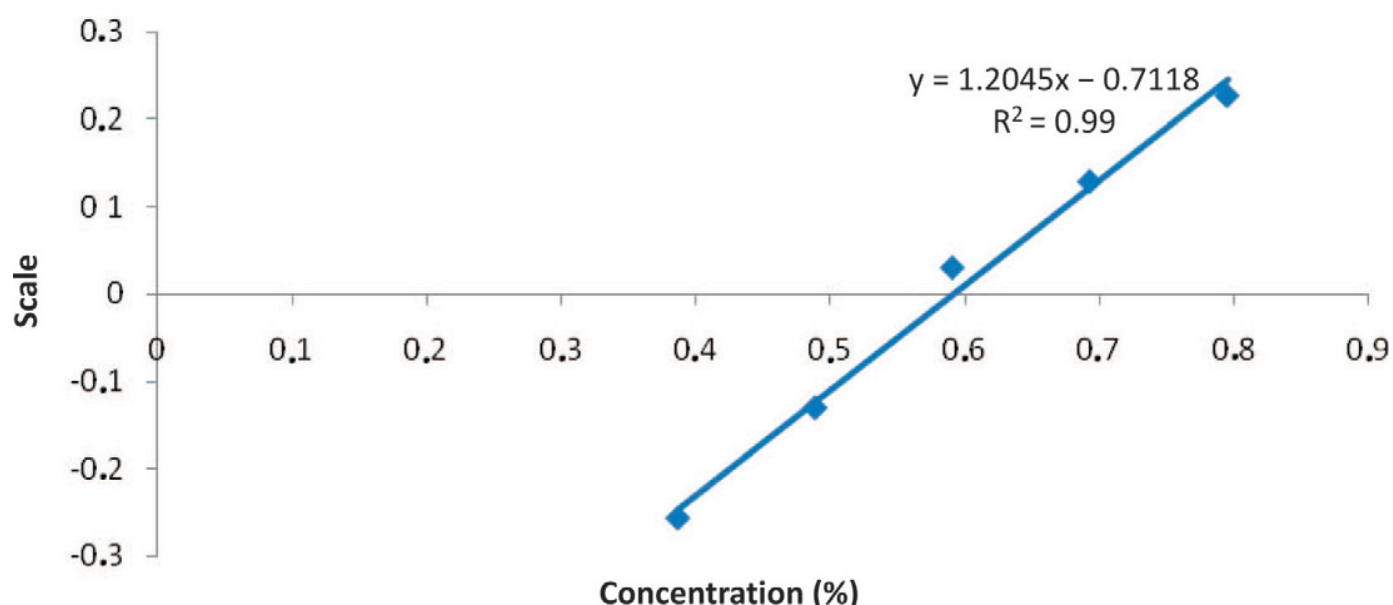

Figure 1. Ideal sucrose concentration to be added to probiotic Petit Suisse cheese, obtained with the use of a just-about-right (JAR) scale. Color version available in the online PDF.

mean derived from the normalized data for sucrose and for the other sweeteners were calculated. The linear regression between Log sweetener concentration (x) and Log geometric mean (y) for sucrose and the sweeteners was calculated with these values, obtaining the linearized results shown in Figure 3.

The values for the angular coefficient, intercept on the ordinate, and coefficient of linear correlation could then be determined from these graphs, as shown in Table 2 . The straight line found was the linearized result of the simple power function $\mathrm{S}=a \cdot \mathrm{C}^{n}$, known as Steven's Law or the Power Function (Moskowitz, 1974), where S is the sensation perceived by the panelists, $\mathrm{C}$ is the concentration of the stimulus (sweetener), $a$ is the antilog of the value $\mathrm{y}$ on the intercept, and $n$ is the angular coefficient of the straight line obtained. By substituting the variables of the function, the equivalent concentration of each sweetener was determined for the probiotic Petit Suisse cheese, as shown in Table 3.

The power of a sweetener is defined as the number of times a compound is sweeter than sucrose, based on its sweetness (Cadena and Bolini, 2012). Various

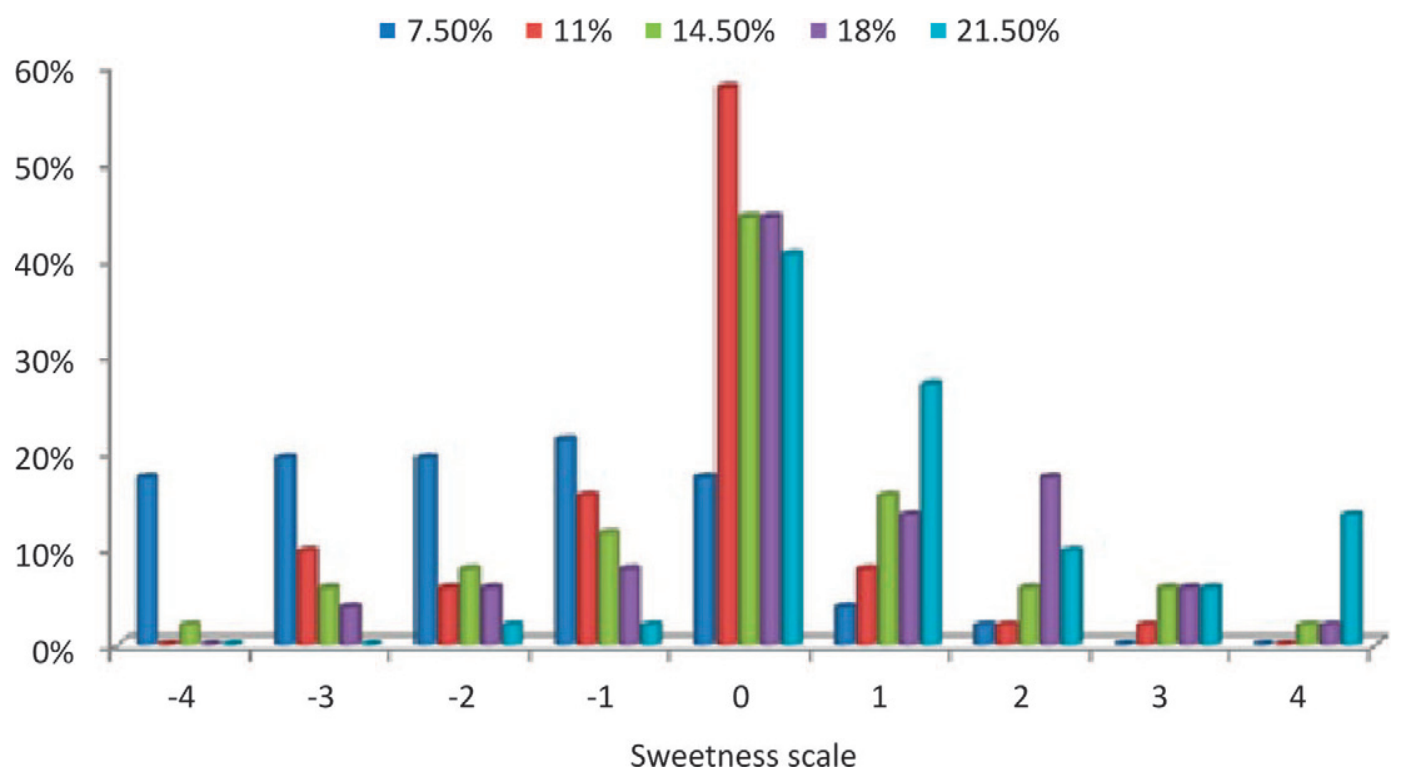

Figure 2. Histograms with the distribution of responses in acceptance test for probiotic Petit Suisse cheese samples with 7.5, 11, 14.5, 18, and $21.5 \%$ sucrose. Color version available in the online PDF. 

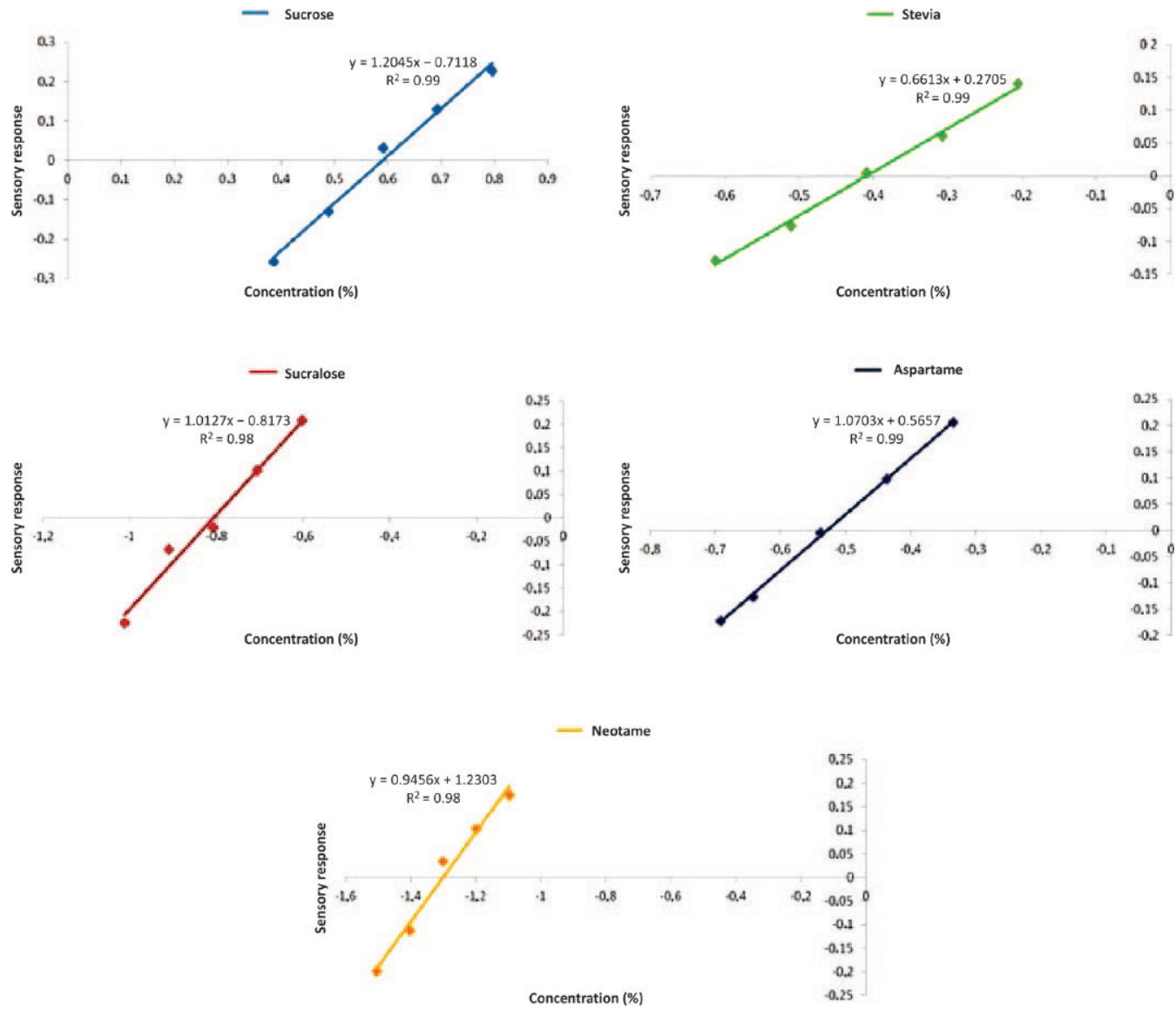

Figure 3. Results of linearized power functions for probiotic Petit Suisse cheeses sweetened with sucrose, stevia, sucralose, aspartame, and Neotame (NutraSweet Corp., Chicago, IL). Color version available in the online PDF.

studies have aimed to determine the sweetening power of sweeteners (Cardoso et al., 2004; Marcellini et al., 2005; Cardoso and Bolini, 2007; De Marchi et al., 2009; Moraes and Bolini, 2010) but no previous studies have been done with probiotic Petit Suisse cheese and the sweeteners used in this study. Thus, the equivalent concentrations found for the sweeteners in this study divided by the sucrose concentration considered ideal
(15.2\% wt/vol) for the probiotic Petit Suisse cheese determined their sweetening powers, as shown in Table 4. According to the data obtained in the present study, the sweetener sucralose was 625 times sweeter in the Petit Suisse cheese than $15.2 \%$ sucrose. This value was identical to that found by De Marchi et al. (2009) in a study on passion fruit juices sweetened with $10 \%$ sucrose. The value found in the present study was close to

Table 2. Values of slope, intercept on ordinate, linear correlation coefficient (r), and power function, obtained in tests using magnitude scale to determine the sweetness equivalence of sweeteners in probiotic Petit Suisse cheese $^{1}$

\begin{tabular}{llrll}
\hline Sweetener & Slope & Intercept & \multicolumn{1}{c}{$\mathrm{r}$} & Power function $^{2}$ \\
\hline Sucrose & 1.2045 & -0.7118 & 0.99 & $\mathrm{~S}=0.038 \cdot \mathrm{C}^{1.2045}$ \\
Sucralose & 1.0127 & 0.8173 & 0.98 & $\mathrm{~S}=43.112 \cdot \mathrm{C}^{1.0127}$ \\
Stevia & 0.6613 & 0.2705 & 0.99 & $\mathrm{~S}=3.475 \cdot \mathrm{C}^{0.6613}$ \\
Aspartame & 1.0703 & 0.5657 & 0.99 & $\mathrm{~S}=13.533 \cdot \mathrm{C}^{1.0703}$ \\
Neotame $^{3}$ & 0.9456 & 1.2303 & 0.98 & $\mathrm{~S}=288.802 \cdot \mathrm{C}^{0.9456}$ \\
\hline
\end{tabular}

${ }^{1}$ Equivalent sweetness to $15.2 \%$ (wt/vol) of sucrose.

${ }^{2} \mathrm{~S}=a \cdot \mathrm{C}^{n}$, where $\mathrm{S}$ is the perceived sensation, $\mathrm{C}$ the concentration of the stimulus, $a$ is the antilog of the value for $\mathrm{y}$ on the intercept, and $n$ is the angular coefficient of the straight line obtained (Moskowitz, 1974; Stone et al., 2012).

${ }^{3}$ NutraSweet Corp. (Chicago, IL). 
Table 3. Concentrations of sucralose, stevia, aspartame, and Neotame in probiotic Petit Suisse cheese determined by magnitude estimation method

\begin{tabular}{lc}
\hline Sweetener & $\begin{array}{c}\text { Concentration of } \\
\text { sweetener }^{1}(\%)\end{array}$ \\
\hline Sucralose & 0.0243 \\
Stevia & 0.1520 \\
Aspartame & 0.0877 \\
Neotame $^{2}$ & 0.0025 \\
\hline
\end{tabular}

${ }^{1}$ Sweetness equivalent to $15.2 \%$ (wt/vol) of sucrose.

${ }^{2}$ NutraSweet Corp. (Chicago, IL).

that found by Cardoso and Bolini (2007) for equivalence in peach nectar sweetened with $10 \%$ sucrose. Cardoso et al. (2004) found powers of 679 and 554 in their study with hot and iced mate tea, respectively, as well as Marcellini et al. (2005) in pineapple juice and Moraes and Bolini (2010) in strawberry-flavored yogurts. However, in a study carried out with conventional Petit Suisse cheese, Souza et al. (2011) found a sweetening power of 262 for sucralose, a value much lower than that found in the present study, which can be explained by the use of different cultures with distinct metabolic profiles. More recently, using the time intensity technique, Palazzo et al. (2011) determined the sweetening power of sucralose in the formulation of diet chocolates. They found that sucralose was 570 times sweeter than sucrose in chocolates sweetened with $43 \%$ sucrose.

The sweetener stevia was only 100 times sweeter than sucrose in the probiotic Petit Suisse cheese, a value identical to that found for the same compound in instant coffees at $9.5 \%$ by Moraes and Bolini (2010). However, Cardoso and Bolini (2007) found a slightly higher value for stevia, whereas Cardoso et al. (2004) determined a value of 116 in hot mate tea. According to Palazzo et al. (2011), stevia showed a sweetening power 200 times greater in chocolates with $43 \%$ sucrose. The value determined in the present study was close to that found by Cavallini et al. (2005) of 94 in mango juice, equivalent to $8 \%$ sucrose.

In the current study, aspartame was shown to be 173 times sweeter than sucrose. Reis et al. (2012), analyzing strawberry-flavored yogurts sweetened with $11.5 \%$ su-

Table 4. Values of sweetening power (number of times that the compound is sweeter than $15.2 \%$ sucrose) determined for sweeteners in probiotic Petit Suisse cheese

\begin{tabular}{lc}
\hline Sweetener & $\begin{array}{c}\text { Sweetening } \\
\text { power }\end{array}$ \\
\hline Sucralose & 625 \\
Stevia & 100 \\
Aspartame & 173 \\
Neotame $^{1}$ & 6,082 \\
\hline
\end{tabular}

${ }^{1}$ NutraSweet Corp. (Chicago, IL). crose, found a sweetening power of 160 for aspartame. Values similar to those found in the present study were also encountered by Moraes and Bolini (2010) for equivalence in instant coffees sweetened with $9.5 \%$ sucrose (187 times sweeter) and by Cardoso and Bolini (2007), who determined a power of times 185 for aspartame in peach nectar sweetened with $10 \%$ sucrose. Marcellini et al. (2005) observed that aspartame presented a sweetening power of 144 times in pineapple juice sweetened with $8.5 \%$ sucrose, and Cavallini et al. (2005) observed a power of 146 for aspartame in mango juice sweetened with $8 \%$ sucrose. In hot mate tea, the power was 163 and was even greater in iced mate tea, with a power of 277 times (Cardoso et al., 2004). Neotame, the most recently discovered artificial sweetener, can present a sweetening power varying from 6,000 to 13,000 times higher than sucrose (Satyavathi et al., 2010). In the present study, this sweetener showed a sweetening power 6,082 times higher than sucrose when evaluated in the probiotic Petit Suisse cheese sweetened with 15.2\% sucrose. Corroborating these data, in a recent study with diet chocolates, evaluating sweetness equivalence by the time intensity data collection method, the sweetening power of Neotame was established as 8,600 (Palazzo et al., 2011). It is worth mentioning the lack of studies on the behavior of this sweetener when added to various types of reduced-calorie foods.

\section{Viability of the Starter and Probiotic Cultures}

Figure 4 shows the viable cell counts for Streptococcus thermophilus, L. acidophilus, and Bifidobacterium lactis in the 5 samples of strawberry-flavored probiotic Petit Suisse cheeses. Initially, the population of the starter culture Streptococcus thermophilus showed good viability in all the samples, with values above 9 $\log \mathrm{cfu} / \mathrm{g}$ in nearly all the samples. Around d 14, all cultures showed a decrease in numbers compared with the initial counts, but maintained values $>8.5 \log \mathrm{cfu} / \mathrm{g}$ until the end of the shelf life, with the exception of the sample containing sucrose, which had counts slightly lower than the others.

The viability of $L$. acidophilus showed little change between the initial and final counts for the majority of samples, with almost all initial values above $7.5 \mathrm{log}$ $\mathrm{cfu} / \mathrm{g}$.

The Bifidobacterium lactis counts showed curious results. Whereas the other cultures analyzed showed a slight loss in viability during storage, the Bifidobacterium lactis counts increased during the first half of the shelf life, reaching values $>7.0 \mathrm{log} \mathrm{cfu} / \mathrm{g}$ in all samples, and then remaining unaltered until the end of storage, with the exception of samples containing aspartame, which showed a slight reduction. 

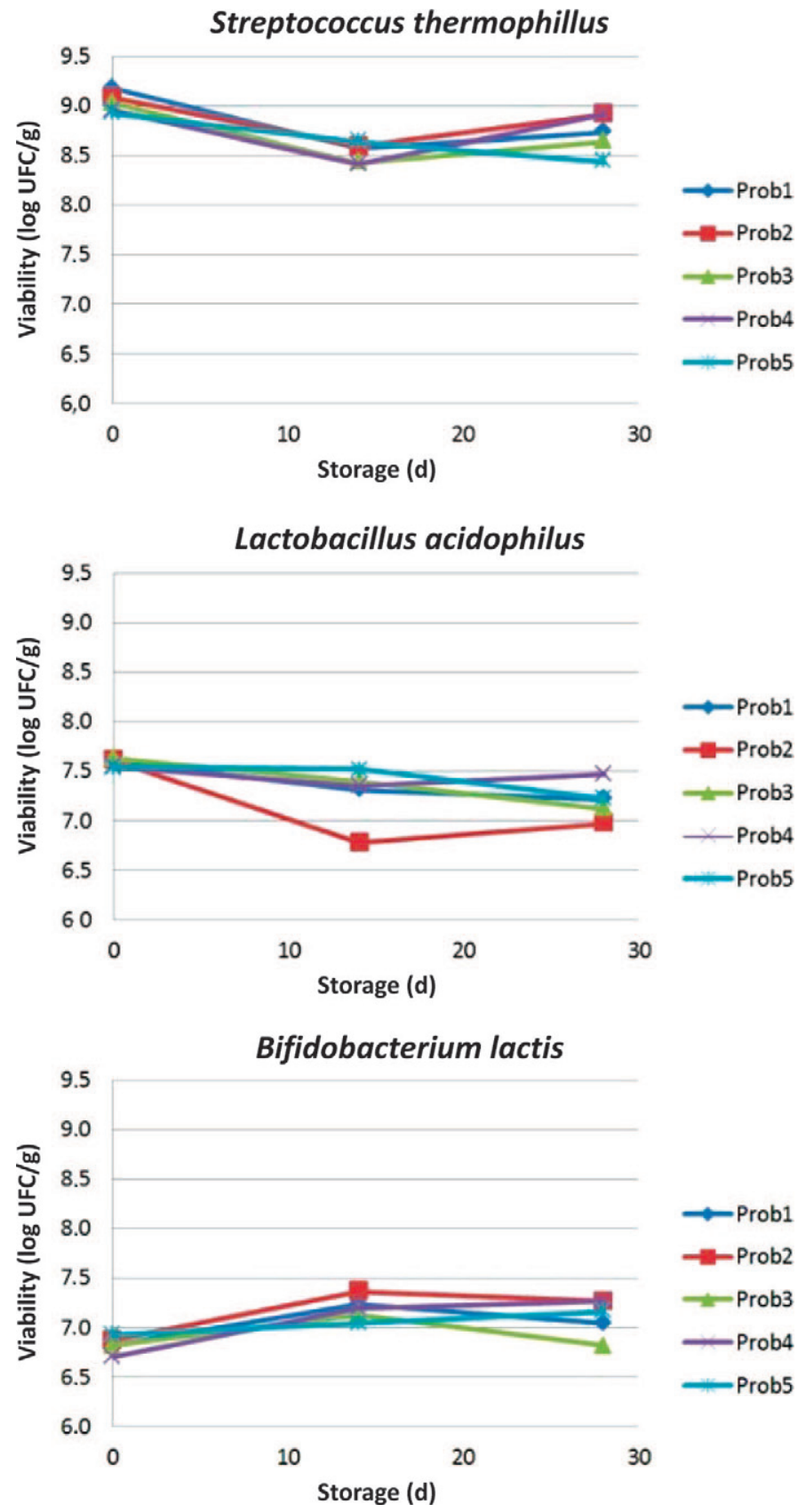

Figure 4. Viability of Streptococcus thermophilus, Lactobacillus acidophilus, and Bifidobacterium animalis ssp. lactis obtained in probiotic Petit Suisse cheese during storage at $4^{\circ} \mathrm{C}$ for $28 \mathrm{~d}$. Color version available in the online PDF.

As in other studies, the cheeses showed satisfactory probiotic bacterial counts (Gomes et al., 2011; Escobar et al., 2012; Lollo et al., 2012; Minervini et al., 2012), because of the protective effects of the food matrix (higher $\mathrm{pH}$ values and greater compactness; Cruz et al., 2009; Granato et al., 2010; Pereira et al., 2010). The viability of Bifidobacterium spp. appears to increase in the presence of other probiotic strains, resulting in elevated values for all microorganisms evaluated (Vinderola et al., 2000; Corrêa et al., 2008). On the other hand, our results suggest the sweeteners had no influence on the metabolism of the probiotic bacteria, which maintained their viability, in accordance with previous studies performed in other foods, such as a wheat-based beverage (Angelov et al., 2006), chocolates (Nebesny et al., 2007), and dairy-based processed foods (Vinderola et al., 2002; Basyigit et al., 2006). However, it is important to emphasize that the sweeteners were added after the fermentation of the base cheese, not during it, which could have resulted in different viability values of the probiotic bacteria. So, this statement should be viewed with caution and additional research should be performed to further investigate this observation.

Based on the results presented, the addition of different sweeteners $-0.024 \%$ sucralose, $0.152 \%$ stevia, $0.088 \%$ aspartame, $0.0025 \%$ Neotame, or $15.2 \%$ sucrose (wt/wt) - to probiotic Petit Suisse cheeses presented no negative effects on the viability of the probiotic bacteria during shelf life, established as $28 \mathrm{~d}$, confirming the potential of these sweeteners for use in low-calorie functional foods. However, future studies should establish the sensory profiles and evaluate consumer acceptability of these products.

\section{CONCLUSIONS}

Petit Suisse cheese is a viable matrix for the application of probiotic microorganisms that allows viable cell counts (required for health beneficial effects) to be maintained throughout the shelf life. The sweeteners used, when added in the concentrations applied here, had no negative effect on the starter and probiotic cultures. Additional studies should be carried out to determine the viability of these microorganisms during a longer storage period and the acceptability of the product by affective and sensory descriptive tests.

\section{REFERENCES}

ABIAD (Associação Brasileira da Indústria de Alimentos Dietéticos e para Fins Especiais). 2011. Adoçante Tire suas Dúvidas. Accessed May 29, 2012. http://www.abiad.org.br/index.php/noticias/83abiad-lanca-cartilha-que esclarece-duvidas-sobre-adocantes.

Amerina, M. A., R. Pangborn, and E. B. Roessler. 1965. Principles of Sensory Evaluation of Food. Academic Press, New York, NY.

Angelov, A., V. Gotcheva, R. Angelov, V. Gotcheva, R. Kuncheva, and T. Hristozova. 2006. Development of a new oat-based probiotic drink. Int. J. Food Microbiol. 112:75-80.

Ares, G., C. Barreiro, and A. Giménez. 2009. Comparison of attribute liking and jar scales to evaluate the adequacy of sensory attributes of milk desserts. J. Sens. Stud. 24:664-676.

Basyigit, G., H. Kuleasan, and G. A. Karahan. 2006. Viability of human-derived probiotic lactobacilli in ice cream produced with sucrose and aspartame. J. Ind. Microbiol. Biotechnol. 33:796-800. 
Brasil Agência Nacional de Vigilância Sanitária. 2008. Resolução n.18 de 24 de Março de 2008. Regulamento Técnico que autoriza o uso de aditivos edulcorantes em alimentos, com seus respectivos limites máximos. Diário Oficial da União, Brasília, Brazil.

Brasil Ministério da Agricultura, Pecuária e Abastecimento. 1996. Portaria $\mathrm{n}^{\mathrm{Q}} 146$, de 07/03/96. Regulamento Técnico de Identidade e Qualidade de Queijos. Ministério da Agricultura, Pecuária e Abastecimento, Brasília, Brazil

Cadena, R. S., and H. M. A. Bolini. 2012. Ideal and relative sweetness of high intensity sweeteners in mango néctar. J. Food Sci. Technol. 47:991-996.

Cardarelli, H. R., F. C. A. Buriti, I. A. Castro, and S. M. I. Saad. 2008. Inulin and oligofructose improve sensory quality and increase the probiotic viable count in potentially synbiotic Petit-suisse cheese. Lebenson. Wiss. Technol. 41:1037-1046.

Cardoso, J. M. P., J. R. Battochio, and H. M. A. Cardello. 2004. Equisweetness and sweetening power of different sweetening agents in different temperatures of consumption of tea drink in soluble power. Cienc. Tecnol. Alim. 47:448-452.

Cardoso, J. M. P., and H. M. A. Bolini. 2007. Different sweeteners in peach nectar: Ideal and equivalent sweetness. Food Res. Int. 40:1249-1253.

Castro, W. F., A. G. Cruz, M. S. Bisinotto, L. M. R. Guerreiro, J. A. F. Faria, H. M. A. Bolini, R. L. Cunha, and R. Deliza. 2013a. Development of probiotic dairy beverages: Rheological properties and application of mathematical models in sensory evaluation. J. Dairy Sci. 96:16-25

Castro, W. F., A. G. Cruz, D. Rodrigues, G. Ghiselli, C. A. F. Oliveira, J. A. F. Faria, and H. T. Godoy. 2013b. Effects of different whey concentrations on physicochemical characteristics and viable counts of starter bacteria in dairy beverage supplemented with probiotics. J. Dairy Sci. 96:96-100.

Cavallini, D. C. U., H. M. A. Bolini, and D. Garcia. 2005. Determination of the relative sweetness and acceptability of cyclamate/saccharin blend, aspartame, sucralose and stevia extract as compared to sucrose at different concentrations in mango juice. Alimentaria 368:106-110.

Corrêa, S. B. M., I. A. Castro, and S. M. I. Saad. 2008. Probiotic potential and sensory properties of coconut flan supplemented with Lactobacillus paracasei and Bifidobacterium lactis, during shelf life of the product. Int. J. Food Sci. Technol. 43:1560-1568.

Cruz, A. G., F. C. A. Buriti, C. B. H. Souza, J. A. F. Faria, and S. M. I. Saad. 2009. Probiotic cheese: Health benefits, technological and stability aspects. Trends Food Sci. Technol. 20:344-354.

Cruz, A. G., W. F. Castro, J. A. F. Faria, S. Bogusz Jr., D. Granato, R. M. S. Celeguini, J. Lima-Pallone, and H. T. Godoy. 2012a. Glucose oxidase: A potential option to decrease the oxidative stress in stirred probiotic yogurt. Lebenson. Wiss. Technol. 47:512-515.

Cruz, A. G., W. F. Castro, J. A. F. Faria, H. M. A. Bolini, R. M. S Celeghini, R. S. L. Raices, C. A. F. Oliveira, M. Q. Freitas, C. A. Conte Júnior, and E. T. Mársico. 2013. Stability of probiotic yogurt added with glucose oxidase in plastic materials with different permeability oxygen rates during the refrigerated storage. Food Res. Int. 51:723-728.

Cruz, A. G., W. F. Castro, J. A. F. Faria, P. C. B. Lollo, J. AmayaFarfan, M. Q. Freitas, D. Rodrigues, C. A. F. Oliveira, and H. T. Godoy. 2012b. Probiotic yogurts manufactured with increased glucose oxidase levels: Postacidification, proteolytic patterns, survival of probiotic microorganisms, production of organic and aroma compounds. J. Dairy Sci. 95:2261-2269.

Cruz, A. G., J. A. F. Faria, E. H. M. Walter, R. R. Andrade, R. N. Cavalcanti, C. A. F. Oliveira, and D. Granato. 2010. Processing optimization of probiotic yogurt containing glucose oxidase using surface response methodology. J. Dairy Sci. 93:5059-5068.

De Marchi, R., R. Mina, and H. M. A. Bolini. 2009. Formulating a new passion fruit juice beverage with different sweetener systems. J. Sens. Stud. 24:698-711.

Epler, S., E. Chambers IV, and K. E. Kemp. 1998. Hedonic scales are a better predictor than just-about-right scales of optimal sweetness in lemonade. J. Sens. Stud. 13:191-197.
Escobar, M. C., M. L. Van Tassell, F. Martínez-Bustos, M. Singh, E. Castano-Tostado, S. L. Amaya-Llano, and M. J. Miller. 2012. Characterization of a Panela cheese with added probiotics and fava bean starch. J. Dairy Sci. 95:2779-2787.

Gagula, M., S. Rutenbeck, L. Pollack, A. V. Ressurection, and H. R. Moskowitz. 2007. The just-about-right intensity scale: Functional analyses and relation to hedonics. J. Sens. Stud. 22:194-211.

Gomes, A. A., S. P. Braga, R. S. Cadena, P. C. B. Lollo, C. Carvalho, J. Amaya-Farfan, J. A. F. Faria, and H. M. A. Bolini. 2011. Effect of the inoculation level of Lactobacillus acidophilus in probiotic cheese on the physicochemical features and sensory performance compared with commercial cheeses. J. Dairy Sci. 94:4777-4786.

Granato, D., G. F. Branco, A. G. Cruz, J. A. F. Faria, and N. P. Shah 2010. Probiotic dairy products as functional foods. Comp. Rev. Food Sci. Food Safety 9:455-470.

Hampson, C. R., H. A. Quamme, J. W. Hall, R. A. MacDonald, M. C King, and M. A. Clif. 2000. Sensory evaluation as a selection tool in apple breeding. Euphytica 111:79-90.

Helle, K. J., W. Bockelmann, J. Schrezenmaier, and M. Deverse. 2003. Cheese and its potential as a probiotic food. Pages 203-225 in Handbook of Fermented Functional Foods. E. R. Farnworth, ed CRC Press, Boca Raton, FL.

Karimi, R., A. Mortazavian, and A. Amiri-Rigi. 2012. Selective enumeration of probiotic microorganisms in cheese. Food Microbiol. $29: 1-9$.

Lawless, H. T., and H. Heymann. 2010. Sensory Evaluation of Food: Principles and Practices. Aspen Publishers, Gaithersburg, MD.

Lollo, P. C. B., A. G. Cruz, P. N. Morato, C. S. Moura, L. B. Carvalho-Silva, C. A. F. Oliveira, J. A. F. Faria, and J. Amaya-Farfan. 2012. Probiotic cheese attenuates exercise-induced immune suppression in Wistar rats. J. Dairy Sci. 95:3549-3558.

MacFie, H. J., N. Bratchell, K. Greenhoff, and L. V. Vallus. 1989. Designs to balance the effect of order of presentation and first-order carry-over effects in hall tests. J. Sens. Stud. 4:129-148.

Marcellini, P. S., T. F. Chaino, and H. M. A. Bolini. 2005. Doçura ideal e análise de aceitação de suco de abacaxi concentrado reconstituído adoçado com diferentes edulcorantes e sacarose. Alim. Nutr. 16:177-182.

Meilgaard, M. T., G. V. Civille and B. T. Carr. 2006. Sensory Evaluation Techniques. CRC Press, Boca Raton, FL.

Meullenet, J. F., R. Xiong, M. Bellman-Horner, S. Zivanovic, P. Dias, H. Fromm, and Z. Liu. 2002. Preference mapping of commercial toasted white corn tortilla chips. J. Food Sci. 67:1950-1957.

Minervini, F., S. Siragusa, M. Faccia, F. Dal Bello, M. Gobbetti, and M. De Angelis. 2012. Manufacture of Fior di Latte cheese by incorporation of probiotic lactobacilli. J. Dairy Sci. 95:508-520.

Mondragón-Bernal, O., M. I. Rodrigues, H. M. Bolini, and F. Maugeri. 2010. Optimization of synbiotic fermented food from hydrosoluble soy extract applying experimental design and sensory analysis techniques. J. Sens. Stud. 25:371-389.

Moraes, P. C. B., and H. M. A. Bolini. 2010. Different sweeteners in beverages prepared with instant and roasted ground coffee: Ideal and equivalent sweetness. J. Sens. Stud. 25:215-225.

Moskowitz, H. R. 1974. Sensation and Measurement: Papers in honor of S. S. Stevens. Reidel Press, Dordrecht, the Netherlands.

Nebesny, E., D. Zyzelewicz, I. Motyl, and Z. Libudzisz. 2007. Dark chocolates supplemented with Lactobacillus strains. Eur. Food Res. Technol. 225:33-42.

Palazzo, A. B., M. A. R. Carvalho, P. Efraim, and H. M. A. Bolini 2011. The determination of isosweetness concentrations of sucralose, rebaudioside and neotame as sucrose substitutes in new diet chocolate formulations using the time-intensity analysis. J. Sens. Stud. 26:291-297.

Pereira, L. C.,, C. H. B. Souza, J. Behrens, and S. M. I. Saad. 2010. Lactobacillus Acidophilus and Bifidobacterium sp. in co-culture improve sensory acceptance of potentially probiotic Petit-Suisse cheese. Acta Aliment. 39:265-276.

Reis, R. C., V. P. R. Minim, H. M. A. Bolini, B. R. P. Dias, L. A Minim, and E. B. Ceresino. 2012. Sweetness equivalence of different sweetners in strawberry flavored yogurt. J. Food Qual. $34: 163-170$. 
Satyavathi, K., P. B. Raju, K. V. Bupesh, and T. N. R. Kiran. 2010. Neotame: High intensity low caloric sweetener. Asian J. Chem. 22:5792-5796.

Siró, I., E. Kápolna, B. Kápolna, and A. Lugasi. 2008. Functional food. Product development, marketing and consumer acceptance- $\mathrm{A}$ review. Appetite 51:456-467.

Souza, V. R., A. C. M. Pinheiro, J. D. S. Carneiro, S. M. Pinto, L. R. Abreu, and C. C. Menezes. 2011. Analysis of various sweeteners in Petit-suisse cheese: Determination of the ideal and equivalent sweetness. J. Sens. Stud. 26:339-345.

Stone, H., R. N. Bleibaum, and H. A. Thomas. 2012. Sensory Evaluation Practices. 4th ed. Academic Press, New York, NY.

Stone, H., and S. M. Oliver. 1969. Measurement of the relative sweetness of selected sweeteners and sweetener mixtures. J. Food Sci. 34:215-222.
Suwansri, S., J. F. Meullnet, J. A. Hankins, and V. K. Griffin. 2002. Preference mapping of jasmine rice for US Asian consumers. J. Food Sci. 67:2420-2431.

Vickers, Z. 1998. Sensory specific satiety in lemonade using a just right scale for sweetness. J. Sens. Stud. 3:1-8.

Vinderola, C. G., G. A. Costa, S. Regenhart, and J. A. Reinheimer. 2002. Influence of compounds associated with fermented dairy products on the growth of lactic acid starter and probiotic bacteria. Int. Dairy J. 12:579-589.

Vinderola, C. G., W. Prosello, D. Ghiberto, and J. A. Reinheimer. 2000. Viability of probiotic (Bifidobacterium, Lactobacillus acidophilus and Lactobacillus casei) and nonprobiotic microflora in Argentinean fresco cheese. J. Dairy Sci. 83:1905-1911. 